\title{
Komposisi botani dan produksi biomasa hijauan di Kecamatan Gunung Toar, Kabupaten Kuantan Singingi Riau
}

\section{Botanical composition and biomassa production of forage in Gunung Toar, Kuantan Singingi District Riau}

\author{
Infitria ${ }^{1 *}$, Pajri Anwar ${ }^{1}$, Jiyanto1 dan Muhajirin² \\ ${ }^{1}$ Program Studi Peternakan Fakultas Pertanian Universitas Islam Kuantan Singingi- \\ Riau \\ ${ }^{2}$ ex-mahasiswa Program Pascasarjana, IPB University \\ *Email Koresponden: Infitria.sumeh@gmail.com
}

\begin{abstract}
Abstrak. Tujuan dari penelitian ini adalah untuk mengetahui jenis hijauan yang tumbuh di Kecamatan Gunung Toar, Kabupaten Kuantan Singingi. Penelitian diawali dengan survey (observasi lapang dan penentuan lokasi) kemudian pengambilan sampel hijauan pada 5 Desa yaitu desa Kampung Baru, Pisang Berebus, Petapahan, Pulau Mungkur, Gunung. Masing-masing Desa diambil 5 lokasi, setiap lokasi diambil 5 titik. Penelitian dilanjutkan dengan identifikasi jenis hijauan dan perhitungan produksi hijauan. Alat yang digunakan untuk pengambilan sampel hijauan terdiri dari kuadran $0,5 \times 0,5 \mathrm{~m}^{2}$, gunting rumput, sabit, kantong plastik ukuran 10 dan ukuran $2 \mathrm{~kg}$, karung, tali plastik, dan alat tulis. Perhitungan hijauan dengan persentase total hijauan, perhitungan produksi hijauan dilakukan dengan rata rata tiap desa. Hasil penelitian menunjukkan bahwa terdapat 10 jenis hijauan, yang terdiri atas rumput, legum dan gulma. Kesimpulan dari penelitian ini adalah hijauan yang paling dominan tumbuh di Kecamatan Gunung Toar adalah dari jenis rumput/gramineae 42,53\%, Rumput Bede (Brachiaria decumbens) 13,94\% dan leguminosae 21,45\%. Produksi biomas hijauan tertinggi di Desa Patabahan 73,44 ton/ha/th.
\end{abstract}

Kata kunci: Hijauan, komposisi botanis, kuadran, keragaman, produksi biomas

Abstract. This study aims to determine the type of forage that grows in Kuantan Singingi District. The research began with a survey (field observation and location determination) and then forages sampling in 5 Village, namely Kampung Baru, Pisang Berebus, Petapahan, Pulau Mungkur and Gunung. Each District was taken 5 locations, each location was taken 4 point. Then proceed with the identification of the type forage. The tools used for forage sampling consisted of a $0.5 \times 0.5 \mathrm{~m}^{2}$ quadrant, grass clippers, sickle, plastic bag size 10 and size $2 \mathrm{~kg}$, sack, plastic rope, and stationery. Calculation of forage by percentage of forage, Calculation of forage production with the average of each village. The results showed that there were 10 types of forage, consisting of grass, legumes and weeds. The conclusion of this study is that the most dominant forage growing in Gunung Toar Sub-District is from the type of grass/gramineae $42.53 \%$, namely, Bede grass (Brachiaria decumbens) $13.94 \%$ and leguminosae $21.45 \%$. The highest forage biomass production in Patabahan Village is 73.44 tons/ha/year.

Keywords: Forages, Botanical composition, Kuadran, Diversity,biomassa production. 
Infitria et al.

ANIMPRO: Conference of Applied Animal Science Proceeding Series

\section{PENDAHULUAN}

Kecamatan gunung toar merupakan salah satu daerah di Kabupaten Kuantan Singingi-RIAU. Gunung toar merupakan daerah yang banyak perbukitan dan memiliki hijauan. Hijauan merupakan kebutuhan utama ternak ruminansia. Hijauan di Kecamtan Gunung Toar terlihat cukup melimpah di sepanjang jalan maupun sungai, akan tetapi jenis dan jumlah produksi hijauannya belum diketahui. Hijauan sangat memengaruhi produktivitas produksi ternak. Produksi hijauan yang maksimal harus diketahui komposisi, jenis dan perbandingan hijauan pada suatu lahan. Suatu lahan dikatakan baik jika perbandingan antara hijuan yaitu rumput dan leguminosa sesuai dengan standar nutrisi. Kompoisi botanis meupakan suatu cara untuk mendeteksi jumlah komposisi umput, legum dan gulma (Tana, 2015). Produksi hijauan pada suat lahan juga dipengaruhi oleh kondisi lahan, manajemen dan musim. Musim mempengaruhi produksi hijauan pada suatu lahan (Muhajirin, 2017).

Produktivitas hijauan pakan di padang penggembalaan dipengaruhi oleh faktor ketersediaan lahan yang memadai, dimana lahan tersebut mampu mencukupi kebutuhan hijauan ternak (Putra, 2018). Selain itu fluktuasi musim juga memberikan dampak dan pengaruh terhadap produktivitas ternak (Umami, 2016).

Rumput merupakan pakan yang paling dibutuhkan oleh ternak ruminansia, pakan yang baik akan memberikan pengaruh produktivitas yang baik pada ternak. Banyak faktor yang mempengaruhi produksi hijauan, salah satunya adalah manajemen. Manajemen yang bagus memebrikan produksi yang banyak dibandingkan manajemen yang kurang baik. Selain itu faktor penyebab rendahnya produksi ternak adalah rendahnya kualitas padang penggembalaan (Siba, 2017). Jenis hijauan dan jumlah hijauan yang tumbuh di Kecamatan Gunung Toar belum banyak teridentiikasi, sehingga perlu dilakukan studi tentang jenis hijauan yang tumbuh di Kecamatan Gunung Toar agar diketahui jenis dan jumlah hijauan yang tumbuh di Kecamatan tersebut. Tujuan dari penelitian ini adalah untuk mengetahui jenis dan produksi hijauan yang tumbuh di Kecamatan Gunung Toar.

\section{MATERI DAN METODE \\ Prosedur}

Penelitian ini dilaksanakan pada bulan Juni sampai Agustus 2020 di lima Desa yang berada di Kecamatan Gunung Toar yaitu desa Kampung Baru, Pisang Berebus, Petapahan, Pulau Mungkur, dan Desa Gunung yang diawali dengan survey untuk menentukan titik lokasi dengan metode purposive sampling (Fachrul, 2006).

\section{Pengambilan sampel hijauan}

Pengambilan sampling hijauan terdiri atas 5 Desa, setiap Desa diambil masing-masing 5 titik lokasi. Pengambilan sampling dengan kuadran (plate meter) berukuran 0,5 x 0,5 m2. Kuadran ditempatkan secara diagonal dengan secara acak pada masing-masing titik yang terpilih. Selanjutnya semua tanaman hijauan yang berada didalam kuadran dipotong setinggi $5-10 \mathrm{~cm}$ dari permukaan tanah atau sampai direnggut oleh ternak (Junaidi dan Sawen 2010). Hijauan yang telah dipotong kemudian dimasukkan ke dalam kantong plastik, kemudian diikat dan diberi label. Selanjutnya hijauan dibawa ke laboratorium untuk timbang dan analisis komposisi botanis serta perhitungan produksi biomassa hijauan.

\section{Perhitungan Komposisi Botanis}

Komposisi botanis dihitung dengan cara penimbangan berat segar hijauan, kemudian dianalisa vegetasi (identifikasi komposisi botanis) tanaman dengan memisahkan berdasarkan jenis tanamannya kemudian ditimbang berdasarkan jenis tanaman. Indentifikasi hijauan dihitung berdasarkan rumus Muhajirin et al. (2017) yaitu setiap jenis hijauan dibagi dengan bobot total hijauan dan dikalikan $100 \%$. Kemudian diidentiikasi jenis hijauan dan ditentukan nama hijauan. 
Infitria et al.

ANIMPRO: Conference of Applied Animal Science Proceeding Series

\section{Perhitungan Produksi Biomassa hijauan}

Perhitungan produksi biomassa hijauan dengan menimbang berat segar hijauan pada saat pengambilan sampel. Hijauan yang telah ditimbang berat segarnya dihitung untuk mendapatkan produksi biomassa hijauan. Produksi biomas dihitung dengan rumus Infitria dan Khalil (2014).

\section{HASIL DAN PEMBAHASAN}

\section{Identifikasi Hijauan}

Berdasarkan hasil identifikasi hijauan yang diambil di Kecamatan Gunung Toar terdapat lima jenis Gramineae, dua jenis leguminosa dan tiga jenis gulma. Jenis hijauan di Kecamatan Gunung Toar telihat pada Tabel.1. Jenis hijauan di Kecamatan Gunung Toar terdapat banyak keragaman. Banyaknya keragaman hijauan yang tumbuh di Kecamatan ini disebabkan karena hijauan pakan tumbuh dialam secara alami, dan faktor manajemen. Banyaknya spesies hijauan yang tumbuh di suatu lahan disebabkan karena faktor manajemen manusia (Infitria, 2014).

Persentase Gramineae Bede (Brachiaria decumbens) lebih banyak dibandingkan dengan jenis rumput yang lainnya yaitu $13,94 \%$ sedangkan paling sedikit yaitu jenis rumput benggala $6,19 \%$. Jenis rumput bede banyak ditemui di kelurahan Kampung Baru yaitu 28,75 sedangkan di kelurahan Pulau Mungkur dan Gunung tidak ditemukannya jenis rumput ini. Jenis rumput Bede (Brachiaria decumbens) selain mudah tumbuh juga tahan terhadap injakan dan musim. Muhajirin $d k k$ (2017) menyatakan bahwa rumput $B$. decumbens merupakan salah satu jenis rumput padang penggembalaan yang memiliki nutrisi dan produksi tinggi, tahan dimusim kemarau, serta tahan dengan injakan ternak.

Ketersediaan tanaman leguminosa sangat diperlukan disuatu lahan pastura karena tanaman leguminosa memiliki nilai nutrisi yang tinggi dibandingkan dengan tanaman rumput. Tanaman leguminosa dalam suatu lahan sangat diperlukan karena memiliki nutrisi yang tinggi dibandingkan dengan rumput (Infitria dan Khalil 2014). Berdasarkan analisa persentase tanaman legum terdapat dua jenis legum yaitu centro (Centrocema pubescens) dan Putri Malu (Mimosa pudica). Persentase legum jenis centro lebih banyak didapatkan di Kelurahan Patabahan yaitu 42,92\% sedangkan di Kelurahan Pisang Gerubus legum jenis centro tidak ditemuinya.

Peningkatan proporsi rumput dan penurunan proporsi leguminosa pada lahan disebabkan oleh keberadaan rumput yang lebih tinggi terutama rumput $B$. decumbens, hal ini dikarenakan tanaman leguminosa adalah tanaman yang lemah bila ditanam campuran dengan rumput (Tosti dan Thorup-Kristensen 2010). Diperkuat oleh Ali (2014) bahwa interspesific competition antara rumput dan leguminosa dapat menurunkan kelangsungan hidup dan menghambat pertumbuhan tanaman yang subdominan (leguminosa).

Jumlah perbandingan hijauan dan leguminosa yang baik pada suatu padang penggembalaan adalah 60:40, 60 rumput dan 40\% legum. Hijauan yang tumbuh di Kecamatan Gunung Toar perbandingan antara rumput dan legum adalah 42,53:21,45\%, hal ini memperlihatkan bahwa perbandingan komposisi hijauannya belum termasuk memenuhi kategori komposisi padang penggembalaan yang baik.

Tabel 1. Jenis hijauan yang tumbuh di Kecamatan Gunung Toar

\begin{tabular}{|c|c|c|c|c|c|c|c|}
\hline \multirow{2}{*}{ No } & \multirow{2}{*}{$\begin{array}{l}\text { Jenis Hijauan } \\
\text { Gramineae }\end{array}$} & \multicolumn{5}{|c|}{ Desa } & \multirow{2}{*}{ Rataan } \\
\hline & & PM & Gn & Ptphn & $\mathrm{KB}$ & PB & \\
\hline & & $\%$ & $\%$ & $\%$ & $\%$ & $\%$ & \\
\hline 1 & Bede (Brachiaria decumbens) & 0,00 & 0,00 & 19,44 & 28,75 & 21,53 & 13,94 \\
\hline 2 & $\begin{array}{l}\text { Rumput Benggala (Panicum } \\
\text { maximum) }\end{array}$ & 0,00 & 0,00 & 0,00 & 0,00 & 30,95 & 6,19 \\
\hline 3 & $\begin{array}{l}\text { Rumput Pahit (Axonopus } \\
\text { compresuss) }\end{array}$ & 0,00 & 15,91 & 13,89 & 15,00 & 0,00 & 8,96 \\
\hline 4 & $\begin{array}{l}\text { Rumput Alang-alang (Imprets } \\
\text { cylindrica }(L) \text { Beauu) }\end{array}$ & 0,00 & 0,00 & 0,00 & 18,75 & 14,58 & 6,67 \\
\hline 5 & Grinting (Cynodon dactylon L. Pers) & 25,00 & 0,00 & 8,83 & 0,00 & 0,00 & 6,77 \\
\hline
\end{tabular}


Infitria et al.

ANIMPRO: Conference of Applied Animal Science Proceeding Series

\begin{tabular}{|c|c|c|c|c|c|c|c|}
\hline \multirow{2}{*}{\multicolumn{8}{|c|}{ Leguminosa }} \\
\hline & & & & & & & \\
\hline 6 & Centro (Centrocema pubescens) & 5,13 & 33,39 & 42,92 & 16,67 & 0,00 & 19,62 \\
\hline \multirow[t]{3}{*}{7} & Putri Malu (Mimosa pudica) & 0,00 & 0,00 & 0,00 & 0,00 & 9,13 & 1,83 \\
\hline & Jumlah & 5,13 & 33,39 & 42,92 & 16,67 & 9,13 & 21,45 \\
\hline & Gulma & & & & & & \\
\hline \multirow[t]{2}{*}{8} & Calincing (Oxallis barrelierı) & 0,00 & 0,00 & 0,00 & 20,83 & 23,81 & 8,93 \\
\hline & $\begin{array}{l}\text { Gulma Siam (Chromolaena } \\
\text { odorata) }\end{array}$ & 0,00 & 50,70 & 14,92 & 0,00 & 0,00 & 13,12 \\
\hline \multirow[t]{2}{*}{10} & Pakis (Cyclosorus parathelyptens) & 69,87 & 0,00 & 0,00 & 0,00 & 0,00 & 13,97 \\
\hline & Jumlah & 69,87 & 50,70 & 14,92 & 20,83 & 23,81 & 36,03 \\
\hline
\end{tabular}

Ket : PM (Pulau Mungkur), Gn (Gunung), Ptphn (Patapahan), KB (Kampung Baru), PB (Pisang Berebus)

\section{Produksi Hijauan dan Kapasitas Tampung}

Perhitungan produksi biomas suatu lahan perlu dilakukan untuk mengetahui produksi hijauan perhari, perbulan atau pertahun. Hasil penelitian bahwa produksi biomas di Kecamatan Gunung Toar tertinggi di dapat pada kelurahan Patabahan yaitu 73,44 ton/ha/th sedangkan Kelurahan Pisang Berebus memiliki produksi biomas terendah yaitu 45,84 Ton/ha/th. Tinggi rendahnya produksi suatu lahan diengaruhi oleh letak lokasi, kesuburan tanah, iklim dan cuaca (Muhajirin, 2017). Kelurahan Patabahan menempati urutan produksi biomas tertinggi hal ini dikarenakan Kelurahan Batabahan merupakan darah pertanian dan perkebunan hasil dari sisa pemupukan suatu tanaman akan memberikan pengaruh terhadap kesuburan tanah sehingga hijauan akan mendapatkan unsur hara dari sisa pemupukan tersebut. Muhajirin 2017 menyatakan bahwa musim mempengaruhi produksi biomas dan kualitas nutrisi hijauan pakan. Produksi hijauan alam juga relatif menurun pada musim kering/kemarau sehingga akan berpengaruh langsung terhadap produktivitas ternak.

Produksi biomas memberikan pengaruh terhadap kapasitas tampung. Produksi biomas yang tinggi akan mendapatkan kapasitas tampung yang tinggi juga, hal ini diperlihatkan pada Tabel 2 bahwa Kelurahan yang memiliki produksi biomas tinggi memiliki kapasitas tampung yang tinggi yaitu Kelurahan Patapahan sebanyak 5,75 ST/ha/th. Whiteman et al. 1974 pertumbuhan dan produksi hijauan makanan ternak dipengaruhi, iklim, spesies dan manajmen.

Tabel 2. Produksi biomas hijauan dan kapasitas tampung ternak di Kecamatan Gunung Toar

\begin{tabular}{ccccccc}
\hline \multirow{2}{*}{ Parameter } & \multirow{2}{*}{ satuan } & \multicolumn{5}{c}{ Desa } \\
\cline { 3 - 7 } & & $\mathrm{PM}$ & $\mathrm{Gn}$ & Ptphn & $\mathrm{KB}$ & $\mathrm{PB}$ \\
\hline Produksi Hijauan & $\mathrm{kg} / \mathrm{ha} / \mathrm{th}$ & 56771,37 & 54158,70 & 73438,00 & 47304,00 & 45844,00 \\
& Ton/ha/th & 56,77 & 54,16 & 73,44 & 47,30 & 45,84 \\
Kapasitas Tampung & $\mathrm{ST} / \mathrm{ha} / \mathrm{th}$ & 4,44 & 4,24 & 5,75 & 3,70 & 3,59 \\
\hline
\end{tabular}

Ket : PM (Pulau Mungkur), Gn (Gunung), Ptphn (Patapahan), KB (Kampung Baru), PB (Pisang Berebus)

\section{KESIMPULAN}

Hijauan yang paling dominan tumbuh di Kecamatan Gunung Toar adalah dari jenis rumput/gramineae $42.53 \%$ yaitu, Rumput Bede (Brachiaria decumbens) $13,94 \%$ dan leguminosae $21.45 \%$. Produksi biomas hijauan tertinggi di Desa Patabahan 73,44 ton/ha/th.

\section{DAFTAR PUSTAKA}

Fachrul MF. 2006. Metode Sampling Bioekologi. Jakarta. Bumi Aksara

Infitria and Khalil. 2014. Studi Produksi Dan kualitas Hijauan Dilahan Padang Rumput Upt peternakan Universitas Andalas. Bul. Makanan Ternak, vol. 101, no. 1, pp. 25-33, 
Junaidi M and D. Sawen. 2010. Keragaman botanis dan kapasltas tampung padang penggembalaan alami Kabupaten Yapen. J. IImu Peternak. dan Vet. vol. 5, no. 2, ,

Mousavi.SA. Eskandari H. 2011. A general overview on intercropping and its advantages in sustainable agriculture. JAEB, vol. 11, no. 1, pp. 482-486,

Muhajirin, Despal, and Khalil. 2017. Pemenuhan kebutuhan nutrien sapi potong bibit yang digembalakan di Padang Mengata. Bul. Makanan Ternak. vol. 104, no. 1, pp. 9-20

Prawiradiputra B. 2003. Sistem Produksi Hijauan Pakan di Lahan Kering DAS Jratunseluna. Jitv, vol. 8, no. 3, pp. 189-195.

Prawiradiputra B. 2007. Gulma padang rumput yang merugikan. Wartazoa, vol. 17, no. 2, pp. 4657 ,

Putra RK, H. P. Nastiti, and Y. H. Manggol. 2018. Komposisi Botani Dan Produksi Hijauan Makanan Ternak Padang Penggembalaan Alam Di Desa Letneo Kecamatan Insana Kabupaten TTU. Nukl. Peternak., vol. 5, no. 1, pp. 42-48.

SIBA, SF. N. SURYANA. 2017. Evaluasi padang penggembalaan alami maronggela di Kabupaten Ngada Provinsi Nusa Tenggara Timur. Majalah IImiah Peternakan. vol. 20, no. 1, pp. 1-4,

Tana, H. P. Nastiti, and S. T. Temu. 2015. Komposisi Botani dan Produksi Hijauan Makanan Ternak Musim Hujan pada Padang Penggembalaan Alam Desa Oesao, Kecamatan Kupang Timur Kabupaten Kupang. J. Nukl. Peternak., vol. 2, no. 2, pp. 144-151,

Umami N. ellentik. Damayanti. 2016. Potensi dan produksi hijauan pakan ternak di lahan pertanian Banyusoco, Playen, Gunung Kidul P. prosisding Simp. Nas. dan Pengemb. Peternak., vol. 53, pp. 82-87,

Hawolambani YU, Herayanti PN, Yoakim HM. 2015. Produksi hijauan makanan ternak dan komposisi botani padang penggembalaan alam pada musim hujan dl Kecamatan Amarasi Barat Kabupaten Kupang. J Nukleus Peternakan. vol. 2, no. 1, pp. 59-65. 